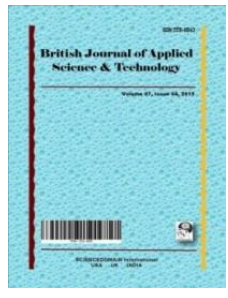

British Journal of Applied Science \& Technology

9(1): 100-107, 2015, Article no.BJAST.2015.250

ISSN: 2231-0843

SCIENCEDOMAIN international

www.sciencedomain.org

\title{
Phenological Cycles, Thermal Time and Growth Curves of Mango Fruit Cultivars in Subtropical Conditions
}

\author{
Jackson Mirellys Azevedo Souza ${ }^{1^{*}}$, Sarita Leonel ${ }^{1}$, Joyce Helena Modesto ${ }^{1}$, \\ Rafael Augusto Ferraz ${ }^{1}$ and Bruno Henrique Leite Gonçalves ${ }^{1}$
}

${ }^{1}$ São Paulo State University/UNESP, School of Agronomic Sciences at Botucatu/FCA, Department of Horticulture, José Barbosa de Barros - 1700 - Entrance I - 18.610-307 - Botucatu-SP, Brazil.

Authors' contributions

This work was conducted in collaboration between all authors. Authors JMAS and SL designed the study, performed the statistical analysis, wrote the first draft of the manuscript and managed literature searches. Authors JHM, RAF and BHLG, along with the author JMAS, held biweekly field analysis throughout the study period, tabulation of data in spreadsheets and sewing tables and graphs. All authors read and approved the final manuscript.

Article Information

DOI: 10.9734/BJAST/2015/18239 Editor(s):

(1) Ahmet Ertek, Department of Agricultural Structures and Irrigation, Suleyman Demirel University, Isaparta \& Turkey.

Reviewers:

(1) Klára Kosová, Crop Research Institute, Prague, Czech Republic. (2) Shoaib Nissar Kirmani, Kashmir University of Agricultural Sciences and Technology, India. Complete Peer review History: http://www.sciencedomain.org/review-history. php?iid=1136\&id=5\&aid=9213

\author{
Original Research Article
}

Received $10^{\text {th }}$ April 2015

Accepted $29^{\text {th }}$ April 2015

Published 11 ${ }^{\text {th }}$ May 2015

\section{ABSTRACT}

There are many mango cultivars available in different regions. It is about time we analysed their productive behavior in these areas, as well as their phenological performance. This study aimed to evaluate: phenological cycles, thermal time and growth curves of mango fruit cultivars in subtropical conditions. For this study we used the following cultivars: Espada Vermelha, Keitt and Palmer. All the experiments were done at UNESP experimental farm in Sao Manuel (SP), during the agricultural cycle from 2012 to 2013 . It was selected 15 branches in each plant, which provided 150 per cultivar. It was determined the number of days of phenological cycles of flowering to fruit ripening, as well as the total number of days to flowering and harvesting. The thermal time was evaluated to each phenological cycle and expressed in accumulation of degree-days. The measurement of the longitudinal diameters (LD) and transverse diameters (TD) of the fruitwere performed in a 12 day's intervals, from the tenth day after the flowers anthesis, to evaluate the 
growth curve. Based on the data, it was found that Keitt cultivar requires more days for the fruit to reach physiological maturity and greater accumulation of degree-days to complete its production cycle. The growth curves of the three varieties of fruits have a simple sigmoidal model in function of the days after anthesis.

Keywords: Mangifera indica L.; phenology; degree-days.

\section{INTRODUCTION}

Brazil is one of the world's major mango producers. In the country, the main cultivar produced is Tommy Atkins. However, Brazilian producers should be targeted to diversify the national matrix in order to increase international competitiveness, constant market fluctuations and instability of consumer preference [1].

Evaluating alternative mango cultivars in different producing regions has become an important tool for the country, since there is a great diversity of cultivars and hybrids available for cultivation, besides different soil and climatic conditions, which influence directly and indirectly on the plant's growth and development.

Such knowledge is crucial to improve crop management, increase productivity and obtain better fruit quality with acceptance by the market. From this study, it is possible to select the best cultivars in each region, according to related characteristics e.g. plants phenology.

Studying the production cycle of Alfa cultivar in Santo Antônio, MT, Barros et al. [2] observed an average of 112 days. In a similar experiment using a 20 years-old Tommy Atkins cultivar with soil-moisture climate interactions in the city of Salinopolis, PA, Rodrigues et al. [3] observed a production cycle of 110-112 days.

Besides the phenological cycles average number of days, the study of thermal time, which a plant needs to complete each of these cycles has also been accomplished. According to Brunini [4], the air temperature directly influences the development and growth of the plant. The use of thermal units system, or degree days, is one way to assess the interactions between climate and plant. As Souza et al. [5] stated, this variable can optimize and reduce climate risks due to the fact that, based on the same, one can define in advance the possible harvest dates, indicating the region climatic potential and activities planning in the field.
In a study on the mango production, thermal time under the northeastern state of Para conditions, Rodrigues et al. [3] found that this cultivar requires an accumulation of $1124.23^{\circ} \mathrm{C}$ day- 1 to $1157.99^{\circ} \mathrm{C}$ day- 1 for the ripening of fruits. While Barros et al. [2], leading experiment in Cuiabana lowland with Alfa mango cultivar, found an accumulation of $2116.50^{\circ} \mathrm{C}$ day-1 for the production cycle of this cultivar with basal temperature of $10^{\circ} \mathrm{C}$.

Based on the literature data, one can see that there is a need to study the phenology cultivars in other different producing regions, notably the ones under warm subtropical climate. Given the above, the objective of this study was to evaluate: phenological cycles, thermal time and growth curves of mango fruit cultivars in subtropical conditions.

\section{MATERIALS AND METHODS}

The study was conducted in Sao Manuel Experimental Farm of Unesp, Faculty of Agricultural Sciences, located at $22^{\circ} 44$ '28 "S and $48^{\circ} 34^{\prime} 37^{\prime \prime} \mathrm{O}$, at $740 \mathrm{~m}$ altitude. The climate of Sao Manuel, according to the Köppen classification, is the type CFA, warm temperate (mesothermal), with rainfall concentrated from November to April (summer) and average annual rainfall of $1376.70 \mathrm{~mm}$, with temperature average of the hottest month above $22^{\circ} \mathrm{C}$ [6]. Climatic data of Sao Manuel for this period, relating to minimum and maximum temperatures and rainfall are shown in Fig. 1.

On the 5th of January, 2008, the orchard was implemented; adopting the spacing of six meters between rows and four feet between plants, with Espada Vermelha, Keitt and Palmer cultivars grafted on Espada Vermelha rootstock. The experiment was carried out when the plants were already in adult stage, with data collected within 2012/2013's agricultural cycle. The cultivation followed the crop technical recommendations [7] and the plants were conducted under spontaneous flowering. 


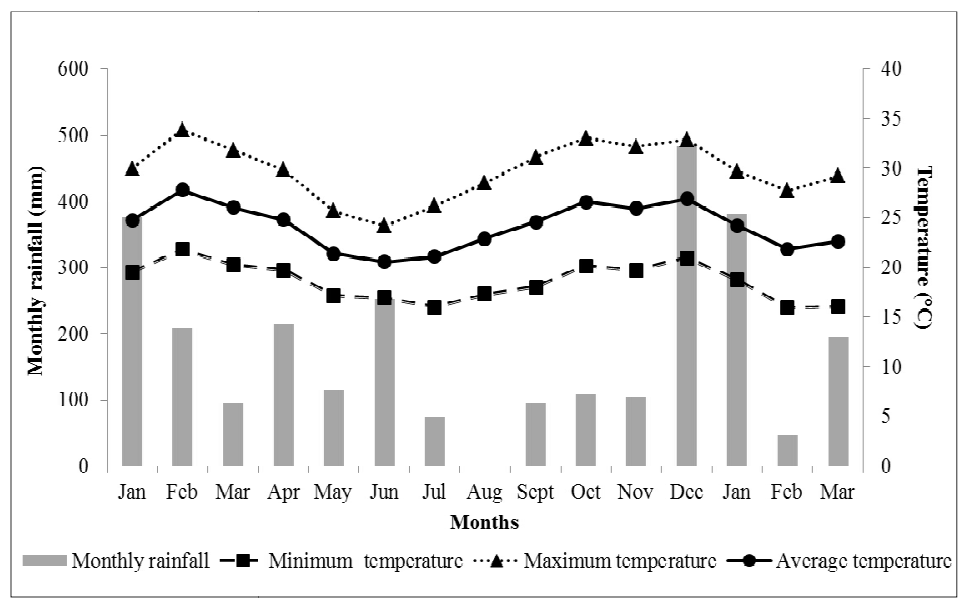

Fig. 1. Maximum, average and minimum temperatures and monthly rainfall of the experimental area. Sao Manuel, SP. 2014

To obtain data concerning the duration of phenological cycles of flowering to fruiting, it was selected and identified in each plant, with EVA platelets, 15 branches with buds in differentiation phase, totaling 150 panicles per cultivar. Until the early flowering, it was carried out weekly visits to the experimental area. After the appearance of the first buds, it was made two visits a week. Based on the methodology proposed by Lucena [8], determined the number of days: from bud differentiation to the complete formation of the panicle, from flowering phase, between anthesis and early natural fruits abortion, from anthesis to fruit formation (in the stage of pellet, marble, egg and fruit), from anthesis to fruit maturity and of harvest stage.

The thermal time quantification of each of the three cultivars to different phenological stages of flowering through fruiting was performed to study the accumulation of degree-days ( $\Sigma G D)$, considering the base temperature of $10^{\circ} \mathrm{C}$. The methodology used was described by Arnold [9]. For the calculation, we used the following equation:

$$
\Sigma G D=\Sigma\left(T_{\max }+T_{\min } / 2\right)-T_{\text {base }},
$$

where:

$$
\begin{aligned}
& \sum_{\text {GD }}=\text { heat units, }{ }^{\circ} \mathrm{C} ; \\
& \mathrm{T}_{\text {max }}=\text { maximum air temperature, }{ }^{\circ} \mathrm{C} \text {; } \\
& \mathrm{T}_{\text {min }}^{\text {min }}=\text { minimum air temperature },{ }^{\circ} \mathrm{C} \text {; and } \\
& \mathrm{T}_{\text {base }}=\text { basal body temperature for the plant }{ }^{\circ} \mathrm{C} .
\end{aligned}
$$

The average and minimum temperatures were obtained by a Vaisala assembly (thermo hygrometer HMP50 + multi-plate under RM Young model 41002) installed at $2 \mathrm{~m}$ height and connected to a Micro logger CR23X sweep every 10 seconds and storage of average data every 5 minutes.

To determine the accumulation of degree-days, it was selected number of degree days required: for formation of the panicle, from the differentiation of flower bud; between anthesis and the stages of pellet, marble, egg, fruit, and between anthesis and full maturation.

It was selected and identified fifteen panicles per plant to evaluate the growth curve of the fruits. In each panicle, it was made the measurement of the longitudinal diameter (LD) and transverse diameter (TD) of the fruit, the 12-days intervals from the tenth day after the flower anthesis. Then, it was also considered the relationship between these two variables to evaluate the fruit shape during the development.

The growth curves of the fruits for TD and LD variables follow a non-linear sigmoidal model, since this is the most common format for analysis of fruit growth. The equations were fitted using the graphics program 'Sigma Plot', with the nonlinear model: $y=a /(1+e-K(X-X c))$. As $a=$ maximum observed value, $\mathrm{e}=$ base of natural logarithm, $\mathrm{k}=$ average rate of growth or accumulation, $\mathrm{X}=$ days after anthesis and $\mathrm{Xc}=$ time to reach half of the maximum growth or accumulation. 
For the LD/TD, revealing the fruit shape and the curves of the three cultivars. It was best fitted to a cubic polynomial model. The mathematical equation followed the following pattern: $y=A X 3$ $+\mathrm{bX} 2+\mathrm{cX}+\mathrm{y} 0$.

We adopted a randomized complete block design with three treatments, corresponding to mango cultivars and 10 repetitions with a useful plant per plot. After obtaining the data, they were submitted to variance analysis test at levels 1 and $5 \%$ probability. When there was significant varianceit means that was compared by Tukey test at $5 \%$.

Descriptive data relating to the seasonality of production and caliber of the fruit did not receive any type of analysis. As the data of fruit growth curves, which were adjusted the mathematical models suitable for this type of analysis.

\section{RESULTS AND DISCUSSION}

With regards to the duration of phenological cycles when it is estimated the number of days to the panicle formation; 'Espada Vermelha' cultivar showed the highest period with an average of 62.67 days, while the lowest number of days was obtained for 'Keitt' cultivar, which panicles completely developed in 44.96 days. On the other hand, 'Palmer' showed an average of 50.37 days for the panicles formatiom (Table 1).

The mango tree flowering is divided into four phases: swelling phase of the apical bud, elongation of the panicle, panicle development stage, flowering and fruiting stage. In this case, the complete development of the panicle comprises the first three phases. Carvalho et al. [10] observed for 'Palmer', a respectively duration of 7, 21 and 15 days for these phases, totaling 43 days to complete the panicle development; this average is similar to the one found in this work for the same cultivar.

In relation to phenological stages of fruiting period, 'Keitt' showed the highest number of days for the fruits to reach the stage of marble, egg and fruit. Except only the number of days to reach the pellet stage, which 'Espada Vermelha' and 'Palmer' had higher number of days (Table 1). Then, the highest number of days observed for 'Keitt' during the last three stages of fruiting may be related to its increased fruit size and for being a cultivar of late cycle. Lucena [8], evaluating 'Tommy Atkins' cultivar phenological stages of flowering to fruiting, it was found an avarege of 2, 15, 33 and 47 days after anthesis to achieve the following stages: pellet, marble, egg and fruit. These results were lower than those of the three cultivars studied in this project, which can be linked to the climate conditions of the cultivation area.

With regards to the number of days to the start of the fruit abortion, there was an average of 24.4 days for 'Espada Vermelha', 34.0 days for 'Palmer' and 40.0 days for 'Keitt' (Table 2). This fact can be explained, because the beginning of the abortion occurred at different times between plants and even between panicles for each cultivar. The study of this variable is important since after the natural fall of the first output is defined the plant production.

In relation to the flowering period, it was found that 'Espada Vermelha' was the one that obtained the highest average of 80.67 days, whilst the lowest average value was for 'Keitt'. Meanwhile, when evaluating the harvest period, the cultivar with the highest number of days was 'Palmer' with 47.40 days, while 'Keitt' showed the lowest average (Table 2).

Table 1. Average Results of panicle formation, pellet stage, marble ball stage, egg stage and fruit stage of the three fruit mango cultivars during the agriculture cycle of 2012/2013, Sao Manuel (SP), 2014

\begin{tabular}{|c|c|c|c|c|c|}
\hline \multirow[t]{2}{*}{ Cultivar } & \multicolumn{5}{|c|}{ Number of days } \\
\hline & $\begin{array}{l}\text { Panicle } \\
\text { formation }^{1}\end{array}$ & Pellet stage $^{2}$ & $\begin{array}{l}\text { Marble ball } \\
\text { stage }^{2}\end{array}$ & Egg stage $^{2}$ & Fruit stage $^{2}$ \\
\hline Esp. Vermelha & $62.67 \mathrm{a}$ & $6.20 \mathrm{a}$ & $22.20 \mathrm{c}$ & $47.00 \mathrm{~b}$ & $58.60 \mathrm{~b}$ \\
\hline Keitt & $44.96 \mathrm{c}$ & $4.20 b$ & $38.60 \mathrm{a}$ & $49.80 \mathrm{a}$ & $63.30 \mathrm{a}$ \\
\hline Palmer & $50.37 \mathrm{~b}$ & $5.60 \mathrm{a}$ & $36.60 \mathrm{~b}$ & $46.60 \mathrm{~b}$ & $54.40 \mathrm{c}$ \\
\hline Average & 52.67 & 5.33 & 32.47 & 47.80 & 58.77 \\
\hline VC (\%) & 2.17 & 20.54 & 4.37 & 1.75 & 1.68 \\
\hline LSD & 1.30 & 1.25 & 1.62 & 0.95 & 1.13 \\
\hline
\end{tabular}


It is of great importance to quantify the number of days during the flowering period to produce quality fruits, because it requires special precautions for irrigation and control, particularly of diseases within this phase. Besides that a producer, who knows the number of days of the harvest, can assist in making important decisions, such as hiring labor and marketing the fruits.

Regarding the production period, it was observed that 'Espada Vermelha' cultivar showed the lowest number of days until fruit ripening, 106.80 days. There was no significant difference for this feature between Palmer and Keitt cultivars. (Table 2).

The smaller number of days of "Espada Vermelha" cultivar reveals its early character compared to 'Keitt' and 'Palmer' cultivars, whose productions are later. However, Souza [11] found that 'Palmer', in tropical conditions, such as in the city of Janaúba (MG), an average of 115 days to complete the fruit maturation, which is probably related to the different climate conditions where the plants were grown.

Several authors have assessed the same characteristic in other cultivars, for example, an average of 112 days until full maturity for Tommy Atkins [3,8] and Alfa [2]. A similar average was also reported by Ventura et al. [12], who observed 115 days for Alfa cultivar in Santo Antonio do Leverger, MT.

In the case of thermal time, it was measured when panicle was developed in the cultivars, specifically from apical bud differentiation to full opening of the flowers. 'Espada Vermelha' stood out as the most demanding in accumulation of degree-days to complete this phenological stage with $591.99^{\circ} \mathrm{C}$. Among the three cultivars, 'Keitt' showed the lowest accumulation of degree-days of $440.47^{\circ} \mathrm{C}$ (Table 3). Lucena [8], evaluating the same variable, it was found that Tommy Atkins had an accumulation of $479.82^{\circ} \mathrm{C}$. While Rodrigues et al. [3] observed the same cultivar, a thermal time in degree-days of $267.05^{\circ} \mathrm{C}$ for flowering.

Table 2. Average Results for beginning of fruits abortion, flowering, harvesting time and fruits full maturity of the three fruit mango cultivars during the agriculture cycle of 2012 / 2013, Sao Manuel (SP), 2014

\begin{tabular}{lllll}
\hline Cultivar & $\begin{array}{l}\text { Number of days for } \\
\text { beginning of fruit } \\
\text { abortion }\end{array}$ & $\begin{array}{l}\text { Number of days } \\
\text { for flowering }\end{array}$ & $\begin{array}{l}\text { Number of } \\
\text { days for } \\
\text { harvesting }\end{array}$ & $\begin{array}{l}\text { Number of days } \\
\text { for full maturity }\end{array}$ \\
\hline Esp. Vermelha & $24.40 \mathrm{a}$ & $80.67 \mathrm{a}$ & $35.80 \mathrm{~b}$ & $106.80 \mathrm{~b}$ \\
Keitt & $40.00 \mathrm{a}$ & $56.96 \mathrm{C}$ & $28.30 \mathrm{C}$ & $191.30 \mathrm{a}$ \\
Palmer & $34.00 \mathrm{a}$ & $62.37 \mathrm{~b}$ & $47.40 \mathrm{a}$ & $154.40 \mathrm{a}$ \\
Average & 32.80 & 66.67 & 37.17 & 150.83 \\
VC (\%) & 46.26 & 1.71 & 2.97 & 0.73 \\
LSD & 17.31 & 1.30 & 1.26 & 1.26 \\
\hline \multicolumn{4}{r}{ Means followed by the same letters within each column are not significantly different according to the Tukey's } \\
test ( $p<0.05){ }^{1}$ Days after anthesis
\end{tabular}

Table 3. Average results in degree-days of panicle formation, pellet stage, marble Ball stage, egg stage, fruit stage and full fruit maturity of the three mango fruit cultivars during the agriculture cycle of 2012/2013, Sao Manuel (SP), 2014

\begin{tabular}{lllllll}
\hline Cultivar & $\begin{array}{l}\text { Panicle } \\
\text { formation } \\
\left({ }^{\circ} \mathbf{C}\right)\end{array}$ & $\begin{array}{l}\text { Pellet } \\
\text { stage } \\
\left({ }^{\circ} \mathbf{C}\right)\end{array}$ & $\begin{array}{l}\text { Marble ball } \\
\text { stage } \\
\left({ }^{\circ} \mathbf{C}\right)\end{array}$ & $\begin{array}{l}\text { Egg stage } \\
\left({ }^{\circ} \mathbf{C}\right)\end{array}$ & $\begin{array}{l}\text { Fruit stage } \\
\left({ }^{\circ} \mathbf{C}\right)\end{array}$ & $\begin{array}{l}\text { Complete } \\
\mathbf{C y c l e}^{1} \\
\left({ }^{\circ} \mathbf{C}\right)\end{array}$ \\
\hline Esp. Vermelha & $591.99 \mathrm{a}$ & $71.87 \mathrm{a}$ & $271.00 \mathrm{~b}$ & $581.41 \mathrm{~b}$ & $737.59 \mathrm{~b}$ & $1433.00 \mathrm{C}$ \\
Keitt & $440.47 \mathrm{C}$ & $51.10 \mathrm{~b}$ & $474.49 \mathrm{a}$ & $637.26 \mathrm{a}$ & $805.46 \mathrm{a}$ & $2476.65 \mathrm{a}$ \\
Palmer & $491.21 \mathrm{~b}$ & $65.29 \mathrm{a}$ & $465.72 \mathrm{a}$ & $583.15 \mathrm{~b}$ & $691.94 \mathrm{C}$ & $2082.05 \mathrm{~b}$ \\
Average & 507.9 & 62.79 & 403.73 & 600.61 & 745.00 & 1997.23 \\
VC (\%) & 2.64 & 19.29 & 3.81 & 2.33 & 1.46 & 0.72 \\
LSD & 15.31 & 13.82 & 17.57 & 16.01 & 12.40 & 16.46 \\
\hline \multicolumn{7}{c}{ Means followed by the same letters within each column are not significantly different according to the } \\
\multicolumn{7}{c}{ Tukey's test (p<0.05) }
\end{tabular}


In relation to phenological stages of fruiting, it was observed that 'Keitt' showed lower thermal time to reach the pellet stage, however, for egg and fruit stages, this cultivar showed the greatest accumulation, 637.26 and $805,46^{\circ} \mathrm{C}$, respectively (Table 3 ). 'Keitt' highest thermal time explains the greatest number of days required for it to complete each phase. Lucena [8] found for 'Tommy Atkins' an accumulation of $40.29^{\circ} \mathrm{C}$ for pellet stage, $237.44^{\circ} \mathrm{C}$ for marble stage, $522.12^{\circ} \mathrm{C}$ for egg stage and $751.22^{\circ} \mathrm{C}$ for fruit stage.

Considering the whole cycle, from anthesis to fruit maturity, the cultivar Keitt showed the highest thermal time of $2476.65^{\circ} \mathrm{C}$, followed by cultivar Palmer, with $2082.05^{\circ} \mathrm{C}$, and the 'Espada Vermelha' to $1433.00^{\circ} \mathrm{C}$ (Table 3). From these data, it is observed that late cultivar Keitt character, as well as early cultivar 'Espada Vermelha', can be related to the amount of heat for performing each of its production cycle, since the three cultivars were conducted under the same cultivation conditions.

Rodrigues et al. [3] found an accumulation from 1124.23 to $1157.99^{\circ} \mathrm{C}$ for Tommy Atkins. However, Barros et al. [2] found a much higher heat accumulation for Alfa $\left(2116.50^{\circ} \mathrm{C}\right)$ These values reinforce the importance of evaluating the thermal time, not only for the different cultivars, but also evaluate the performance of the same cultivar in the different cultivation conditions, since the results are contradictory in the literature.

For the growth curves of the mango tree fruits cultivars, it was found that both longitudinal length and transverse diameter behaved sigmoidal model, as a result of the number of days after anthesis, independently of the assessed cultivar (Figs. 2A and 2B). This result is in agreement with that reported by Ventura et al. [12], who observed, through fresh fruit weight, this same growth behavior to cultivate Alfa in the state of Mato Grosso.

It was observed, during juvenile phase of the growth curve (up to 21 days), that the increase of longitudinal and transverse diameters occurred slowly. Only in the second phase, there was strong growth. This phase of accelerated growth, for both longitudinal and transverse diameter extended up to 82 days for Keitt and Palmer cultivars. For the 'Espada Vermelha' the accelerated growth was until 70 days after anthesis (Figs. 2A and 2B).
Regarding of the longitudinal and transverse diameters slowly increasement, it was found after the 82 days for Keitt and Palmer cultivars, and 70 days for 'Espada Vermelha', which characterizes the fruit ripening stage (Figs. $2 \mathrm{~A}$ and $2 \mathrm{~B}$ ). The knowledge of fruit growth curve allows us to know, for example, the extent to which the plant needs more water and can assist in the management of irrigation, since fruit growing demand higher amounts of water and solutes. Being such an important knowledge to farmers, especially in the regions, with the weather already mentioned, since climatic factors directly influence the fruit development period.

Comparing the behavior of the growth curves of the three cultivars, it was observed that up to 70 days the 'Espada Vermelha' fruits showed greater longitudinal length, however, at this point, Palmer's fruit began to exhibit higher values for this feature (Fig. 2A). In relation to the transversal diameter, it was found that up to 58 days after anthesis these three cultivars presented similar values, only at this point there was a greater difference between them, Keitt's fruit produce higher values followed by 'Palmer' and 'Espada Vermelha' fruits (Fig. 2B).

Unlike the fruit growth curves behaviour for the longitudinal and transverse diameters performed when the relationship between these two characteristics, in order to analyze the format of the result, it was found that the curve followed a standard cubic polynomial as a function of days after anthesis (Fig. 2C).

Throughout the development period of fruits, they had rounded shape, with close to 1 ratio, or elongated ratio $>1$. For the three varieties, the fruit when in pellet stage (between 4 and 6 days), were rounded and only began to lengthen after reaching the egg stage, 20 days after anthesis. 'Espada Vermelha' fruits are lengthened to 58 days after anthesis (Fig. 2C). To the Keitt and Palmer fruits were found that the elongation peak at 70 days of anthesis, while the fruits of 'Espada Vermelha' is lengthened to 58 days after anthesis (Fig. 2C).

The comparisons among the three cultivars, related to fruit shape behavior during its development, showed that the fruits of the 'Espada Vermelha' remained more elongated than the others, throughout the study period. The fruits of 'Keitt' were those with values closer to 1 , that is, those who remained more rounded (Fig. 2C). 
A

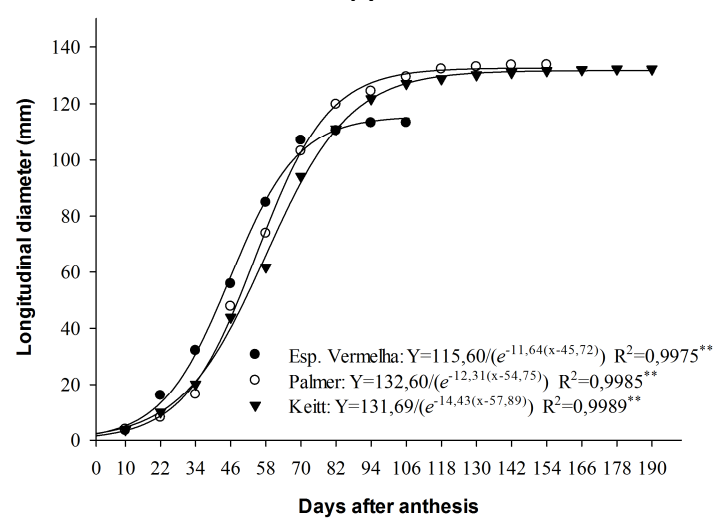

Days after anthesis

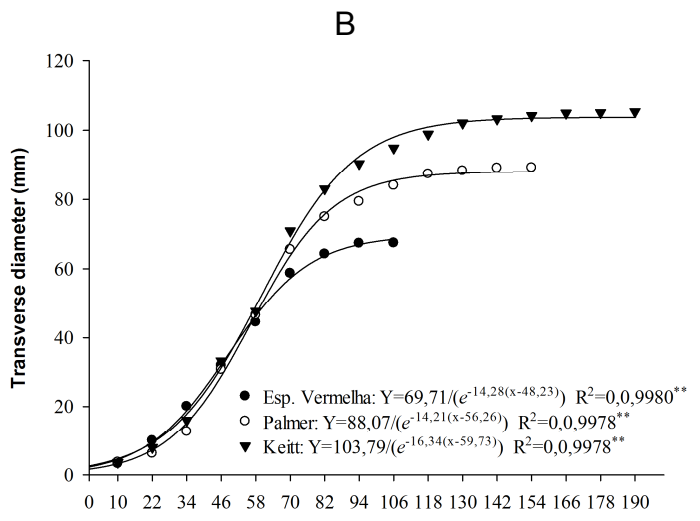

Days after anthesis

C

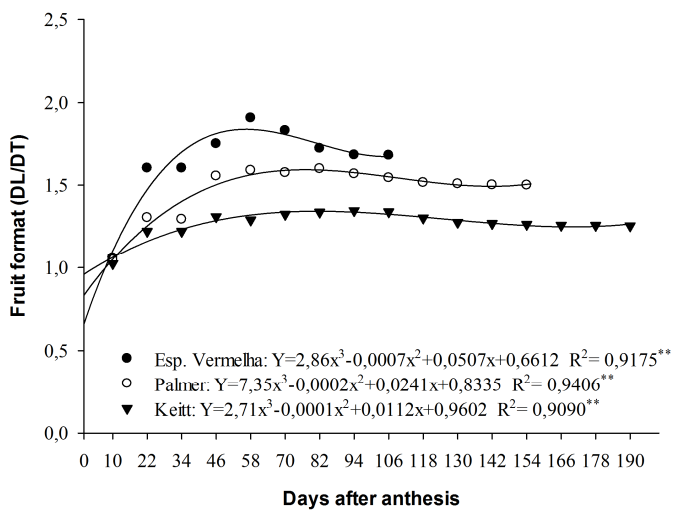

Fig. 2. Longitudinal Diameter (A), transverse diameter (B) and format (C) of the mango fruit cultivars, related to the days after anthesis Sao Manuel, SP. 2014

\section{CONCLUSION}

The cultivar Keitt needs more days to reach physiological maturity of its fruit, as well as it needs further accumulation of degree-days to complete the production cycle. The growth curves of the fruits of three cultivars form a simple sigmoid function in the days after flowering in subtropical conditions.

\section{COMPETING INTERESTS}

Authors have declared that no competing interests exist.

\section{REFERENCES}

1. Lima Neto FP, Santos CAF, Santos RO, Costa TPP. Rating of mango hybrids between monoembryonic varieties in a crop, the Semi-Arid Region. Brazilian Congress of Fruit: Proceedings of the $21^{\text {st }}$ Brazilian Congress of Fruit; Brazil.
Jaboticabal: Brazilian Society of Fruit Crops; 2010.

2. Barros MP, Zanetti VB, FRAGA CIM, Nince CPC. Campelo Junior JH, Wolf FA. Photothermal units and lower base temperature of Alfa mango tree fruit in cuiabana lowland. Brazilian Fruits Journal. 2010;32(2):479-85.

3. Rodrigues JC, Souza PJOP, Lima RT. Estimated baseline and thermal requirement temperatures of mango tree fruit in the northeastern state of Pará. Brazilian Fruits Journal. 2013;35(1):14350.

4. Brunini O. Meteorological elements and plant performance. $1 \mathrm{ft}$ ed. Campinas (SP): IAC. 1998;46.

5. Souza AP, Silva AC, Leonel S, Escobedo $\mathrm{JF}$. Basal temperature and thermal time in the fig tree pruned at different times. Brazilian Fruits Journal. 2009;31(2):31422. 
6. Cunha AR, Martins D. Climate classification for the city of Sao Manuel and Botucatu, SP. Irriga. 2009;14(1):1-11.

7. Manica I, Icuma IM, Malavolta E, Ramos VHV, Oliveira Junior ME, Cunha MM, Junqueira NTV. Mango: technology, production, agribusiness and export. 1st ed. Porto Alegre: Five Continents. $2001 ; 617$.

8. Lucena EMP. Development and physiological maturity of mango 'Tommy Atkins' in the Sao Francisco valley [Doctoral dissertation]. Fortaleza (CE): Federal University of Ceará; 2006.

9. Arnold CY. Maximum-minimum temperatures as a basis for computing heat units. Journal of the American Society for Horticultural Sciences. 1960;76:682-92.

10. Carvalho LM, Lemos JP, Vieccelli JC, Brandão FM, Siqueira DL. Inflorescence development of 'Palmer' mango tree in Viçosa. Latin American $\mathrm{MSI}$ and Latin American MGS: Proceedings of the $13^{\text {th }}$ Latin American Meeting of Scientific Initiation and $9^{\text {th }}$ Latin American Meeting of Graduate Studies; Brazil. Sao Jose dos Campos: UNIVAP; 2009.

11. Souza FV. Growth curve, nutrient export and sodium per Palmer, Haden and Tommy Atkins mango trees fruit [Master thesis]. Jaboticabal: State University Júlio de Mesquita Filho, Faculty of Agricultural and Veterinary Sciences; 2007.

12. Ventura FM, Machado MG, Martins AL, Campelo Junior JH, Wolf FA, Ortiz CER, Martins CA. Baseline temperatures for the Alfa mango fruit growth. Bioscience Journal. 2014;30(2):467-74.

(c) 2015 Souza et al.; This is an Open Access article distributed under the terms of the Creative Commons Attribution License (http://creativecommons.org/licenses/by/4.0), which permits unrestricted use, distribution, and reproduction in any medium, provided the original work is properly cited.

Peer-review history:

The peer review history for this paper can be accessed here: http://www.sciencedomain.org/review-history.php?iid=1136\&id=5\&aid=9213 